\title{
Analisis Penurunan Kadar Cr, Cd DAN Pb Limbah Laboratorium Dasar Ppsdm Migas Cepu Dengan Adsorpsi Serbuk Eceng Gondok (Eichornia crassipes)
}

\author{
Rivaldo Herianto*, M. Arsyik Kurniawan \\ ${ }^{a}$ Program Studi Kimia, Universitas Islam Indonesia KampusTerpadu UII, Jl. Kaliurang Km 14, \\ Sleman, Yogyakarta 55584 \\ *e-mail: heriantorivaldo@gmail.com
}

\section{INTISARI}

Beragam bahan kimia berbahaya digunakan dalam kegiatan di laboratorium. limbah laboratorium memiliki kekhususan sebab biasanya jumlah limbah tidak banyak namun memiliki keragaman yang sangat tinggi. Jenis bahan yang digunakan dapat berubah dari waktu ke waktu bergantung aktivitas dalam laboratorium tersebut. Telah dilakukan penelitian tentang pengolahan penurunan kadar limbah laboratorium dasar PPSDM CEPU dengan menggunakan serbuk eceng gondok. Penelitian ini bertujuan untuk mendapatkan dosis dengan variasi dosis serbuk eceng gondok (Eichornia crassipes) yang tepat dalam proses pengolahan penurunan kadar limbah lab. Parameter uji yang diamati adalah $\mathrm{Cd}, \mathrm{Cr}$ dan $\mathrm{Pb}$ dengan menggunakan metode analisis AAS. Hasil penelitian menunjukkan bahwa efektifitas penurunan kadar konsentrasi limbah labolatorium dasar PPSDM CEPU pada dosis serbuk 0,45 gram.

Kata-kata Kunci : Eceng gondok, Kadar Cd, Cr, Pb, Spektrofotometer Serapan Atom

\begin{abstract}
A variety of hazardous chemicals used in the laboratory. Labolatory wastes have specificity because usually the amount of waste is not much but it has a very high diversity. The type of the material used may change from time to time dependent activities in the labolatory. Has done research about the processing of basic labolatory waste levels decrease PPSDM CEPU by using powder water hyacinth. This research aims to get a dose of the powder dose variation with water hyacinth(Eichornia crassipes) the right in the process effluent levels decrease processing lab. The test parameters were observed was the $\mathrm{Cd}, \mathrm{Cr}$ and $\mathrm{Pb}$ by using methods of the analysis of the AAS. The results showed that the effectiveness of laboratory waste concentration levels decrease basis CEPU on the dose powder PPSDM 0.45 grams.
\end{abstract}

Key Words: Absorption Spectrophotometer Atomic,Eichornia crassipes, the levels of $\mathrm{Cd}, \mathrm{Cr}, \mathrm{Pb}$.

\section{Pendahuluan}

Air merupakan salah satu sumber kehidupan bagi umat manusia. Apabila air telah tercemar maka kehidupan manusia akan terganggu. Hampir semua mahluk hidup di muka bumi ini memerlukan air, dari mikroorganisme sampai mamalia. Tanpa air tiada kehidupan di muka bumi ini (Fardiaz, 
2003). Dewasa ini air menjadi masalah yang perlu mendapat perhatian yang seksama dan cermat. Pencemaran air merupakan masalah regional maupun lingkungan global yang sangat berhubungan dengan penggunaan lahan tanah atau daratan.

Beberapa jenis bahan kimia untuk pupuk dan pestisida pada lahan pertanian akan terbawa oleh air ke daerah sekitarnya sehingga dapat mencemari air permukaan dan menyebabkan erosi (Darmono, 2010). Berbagai penelitian terdahulu menunjukkan manfaat dari eceng gondok (Eichornia crassipes). Syahrul (1998) menyatakan bahwa eceng gondok mampu tumbuh dengan baik dan menyerap zat organik non biodegradable yang terkandung dalam air limbah domestik dengan kadar COD kurang lebih $400 \mathrm{mg}$ COD/L dengan syarat dipenuhinya unsur-unsur hara yang dibutuhkan dan tingkat keasaman diatur maksimum pada pH kurang lebih 8 . Selanjutnya Nugraheni dan Trihadaningrum (2002) menjelaskan tingginya daya serap eceng gondok terhadap unsur $\mathrm{Cd}, \mathrm{Hg}$, dan Ni. Effendi (1983, dalam Nugraheni,2002) meneliti kemampuan penyerapan $\mathrm{Na}$ sebesar 9,8\% dari 228,6 mg/L Na dan $\mathrm{Cl}$ 19,3\% dari 628,1 mg/L Cl. Penelitian lain yang dilakukan oleh Hasim (2003) menyatakan bahwa eceng gondok mampu menurunkan kadar besi $(\mathrm{Fe})$.

Pengolahan air limbah menjadi air bersih dapat dilakukan dengan tiga cara yakni pengolahan secara fisik, kimia, dan biologi. Pengolahan yang paling sederhana dan tidak membutuhkan biaya adalah pengolahan secara biologi, salah satunya dengan menggunakan tumbuhan Eichornia crassipes. Metode yang akan dilakukan adalah adsorpsi dalam upaya untuk mengetahui penurunan kadar logam berat $\mathrm{Pb}$, $\mathrm{Cr}$ dan $\mathrm{Cd}$ oleh tumbuhan Eichornia crassipes pada limbah cair laboratorium dasar PPSDM MIGAS CEPU.

Penelitian bertujuan menentukan adanya kandungan logam berat khususnya $\mathrm{Cd}, \mathrm{Pb}$ dan $\mathrm{Cr}$ pada limbah cair laboratorium dasar PPSDM MIGAS CEPU, mengetahui pengaruh pemberian dosis derbuk eceng gondok (Eichornia crassipes) pada limbah logam berat khususnya $\mathrm{Cd}, \mathrm{Pb}$ dan $\mathrm{Cr}$ pada limbah cair laboratorium dasar PPSDM MIGAS CEPU. Dalam pelaksanaannya ditentukan kadar senyawa-senyawa penting limbah cair laboratorium dasar PPSDM MIGAS CEPU sebelum dan sesudah pemberian serbuk eceng gondok (Eichornia crassipes). 


\section{Metode Penelitian}

\subsection{Alat}

SSA SpectraAA 220FS, Oven pemanas, stirrer dan Pengaduk magnet, Saringan membrane $0,45 \mu \mathrm{m}$, Pipet ukur 10 $\mathrm{mL}$ dan $100 \mathrm{~mL}$, Erlenmeyer $125 \mathrm{~mL}$ dan $250 \mathrm{~mL}$, Labu ukur $50 \mathrm{~mL}$ dan $100 \mathrm{~mL}$, gelas beker $500 \mathrm{~mL}$. Corong gelas.

\subsection{Bahan}

Bahan penelitian terdiri dari: air limbah cair cair laboratorium dasar PPSDM MIGAS CEPU $500 \mathrm{~mL}, 200$ gram serbuk daun Eceng gondok (Eichornia crassipes), Larutan induk $\mathrm{Pb} 1000$ ppm, Larutan induk Cr 1000 ppm, Larutan induk Cd 1000 ppm, $\mathrm{HCl}$ 0,01 M $1 \mathrm{~mL}$.

\subsection{Metode}

Tanaman eceng gondok (Eichornia crassipes) yang diperoleh, daunnya dipisahkan dari akar dan batangnya kemudian dicuci dengan aquades. Setelah itu daun tersebut dikeringkan dengan oven dengan suhu $90{ }^{\circ} \mathrm{C}$ selama 2 jam sampai diperoleh berat konstan. kemudian daun tersebut ditumbuk sampai halus dan kemudian diayak dengan menggunakan ayakan 120 mesh setelah itu serbuk sisa kemudian diayak kembali dengan ayakan 150 mesh, sehingga serbuk akhir yang dihasilkan yakni berupa serbuk kasar atau disebut aksel. Kemudian serbuk dicuci menggunakan $\mathrm{HCl} \quad 1 \quad \mathrm{~mL}$ untuk mengilangkan kontaminasi dalam serbuk, dan di oven kembali, didapat serbuk eceng gondok.

\subsection{Tahap uji limbah dengan variasi dosis serbuk eceng gondok (Eichornia crassipes)}

Air limbah yang mengandung $\mathrm{Pb}$, $\mathrm{Cd}$, dan $\mathrm{Cr}$ diambil sebanyak $50 \mathrm{~mL}$ masingmasing dimasukkan ke dalam erlemeyer 250 $\mathrm{mL}$, kemudian ditambahkan serbuk daun eceng gondok dengan variasi dosis 0,25 gram, 0,35 gram dan 0,45 gram. Selama proses adsorpsi dilakukan pengadukan (pengocokan) dengan stirerr selama 60 menit. Setelah itu air limbah difiltrasi untuk memisahkan partikel serbuk eceng gondok (Eichornia crassipes) dan kemudian filtrat dianalisis.

\section{Hasil dan Pembahasan}

Percobaan ini dilakukan di Laboratorium dasar PPSDM MIGAS CEPU. Sampel yang digunakan berasal dari Limbah cair pada Laboratorium dasar PPSDM MIGAS CEPU. Sampel limbah buangan bekas dari analisis pada laboratorium. Penelitian ini menggunakan metode adsorpsi dari serbuk eceng gondok (Eichornia crassipes).

Metode yang digunakan untuk analisis logam pada limbah cair Laboratorium adalah dengan metode Spektrofoto- 
meter Serapan Atom (AAS) yang dilakukan di laboratorium. Spektrofotometer Serapan Atom merupakan suatu alat yang dapat digunakan untuk analisis kuantitatif. Analisis kuantitatif digunakan untuk mengetahui kadar dari suatu zat dari suatu sampel. Pada analisis ini, Spektrofotometer Serapan Atom digunakan untuk mengetahui kadar $\mathrm{Cr}, \mathrm{Cd}$ dan $\mathrm{Pb}$ dari sampel limbah cair laboratorium dasar PPSDM MIGAS CEPU yang diperoleh dari PPSDM MIGAS CEPU.

\subsection{Preparasi Pembuatan Serbuk Eceng} Gondok (Eichornia crassipes)

Sampel eceng gondok berasal dari Desa Kelurahan Trembul Kecamatan Ngawen Blora. Sempel dipisahkan terlebih dahulu dari akar dan batang. kemudian sampel dicuci dengan aquades untuk mengilangkan kotoran pada eceng gondok (Eichornia crassipes), keringkan dengan menggunakan suhu kamar yaitu $25-27{ }^{\circ} \mathrm{C}$ untuk mengurangi kadar air sebelum masuk oven. Setelah kering sampel dimasukan kedalam oven dengan temperatur $90{ }^{\circ} \mathrm{C}$ selama 2 jam, fungsi dari pemanasan untuk mengilangkan kadar air dalam sempel secara maksimal. Setelah kering sempel ditumbuk dengan mortar agar menjadi serbuk. Serbuk yang sudah jadi dicuci dengan larutan HCL sebanyak $1 \mathrm{ml}$ untuk menghilangkan dari kontaminasi. Serbuk difiltrat kemudian di masukan kedalam oven kembali dengan temperatur $90^{\circ} \mathrm{C}$ selama 2 jam. Serbuk ditimbang dengan analitik dengan variasi dosis $0,25,0,35$ dan 0,45 gram.

\subsection{Analisis Kandungan Logam $\mathrm{Cr}$, $\mathrm{Cd}$ Dan Pb}

Persamaan regresi linear kurva standar yang diperoleh dari grafik hubungan antara konsentrasi dan absorbansi deret standar konsentrasi Cd yaitu 0,2;0,4;0,6; 0,8 dan 1,0 ppm, pada deret standar $\mathrm{Pb}$ dan Cr 1,0;2,0;3,0;4,0 dan 5,0 ppm, dimana $\mathrm{Y}$ $=\mathrm{bx}+\mathrm{a}$, maka diperoleh kurva baku masing-masing logam pada Gambar 1. Kandungan logam $\mathrm{Cr}, \mathrm{Cd}$ dan $\mathrm{Pb}$ pada limbah cair laboratorium dasar PPSDM MIGAS CEPU dapat dillihat pada Tabel 1.

Tabel 1. Kadar limbah cair laboratorium dasar PPSDM MIGAS CEPU

\begin{tabular}{|c|c|}
\hline $\begin{array}{l}\text { Kandungan } \\
\text { limbah cair } \\
\text { lab kimdas } \\
\text { PPSDM } \\
\text { CEPU }\end{array}$ & Kadar (ppm) \\
\hline $\mathrm{Pb}$ & 0,753 \\
\hline $\mathrm{Cd}$ & 1,090 \\
\hline $\mathrm{Cr}$ & 2,502 \\
\hline
\end{tabular}

Hasil analisis untuk parameter $\mathrm{Cr}, \mathrm{Cd}$ dan $\mathrm{Pb}$ pada limbah cair lab dasar ppsdm cepu menunjukkan bahwa kadar $\mathrm{Cr}$ terdapat pada sampel yaitu sebesar 2,502 ppm, Cd 1,090 ppm dan $\mathrm{Pb} 0,753$ ppm, yang berarti limbah cair laboratorium dasar PPSDM MIGAS CEPU menunjukan adanya 
kandungan logam pada limbah cair tersebut setelah di analisis dengan Spektrofotometer Serapan Atom (AAS). Dari data hasil penelitian didapatkan nilai korelasi antara absorbansi dengan kadar (ppm) $\mathrm{Cr}, \mathrm{Cd}$ dan $\mathrm{Pb}$ dimana nilai $\mathrm{R}$ nya yaitu $0,997,0,9944$ dan 0,9987 .

\subsection{Adsorpsi Limbah dengan Serbuk Eceng Gondok}

Setelah mengetahui kandungan logam pada limbah perlakuan selanjutnya ialah pemberian variasi dosis pada limbah cair yaitu $0,25,0,35$ dan 0,45 g. Dengan mengambil limbah $50 \mathrm{~mL}$ dimasukan ke dalam erlenmeyer $125 \mathrm{~mL}$ kemudian ditambahkan masing-masing serbuk eceng gondong (Eichornia crassipes) dengan variasi dosis. Setelah itu stirerr limbah yang sudah diberi serbuk selama 1 jam untuk maksimalkan adsorpsi pada limbah, kemudian disaring dan diambil filtrat dan dianalisis dengan AAS secara duplo hal ini diperlukan meningkatkan keakuratan analisis.

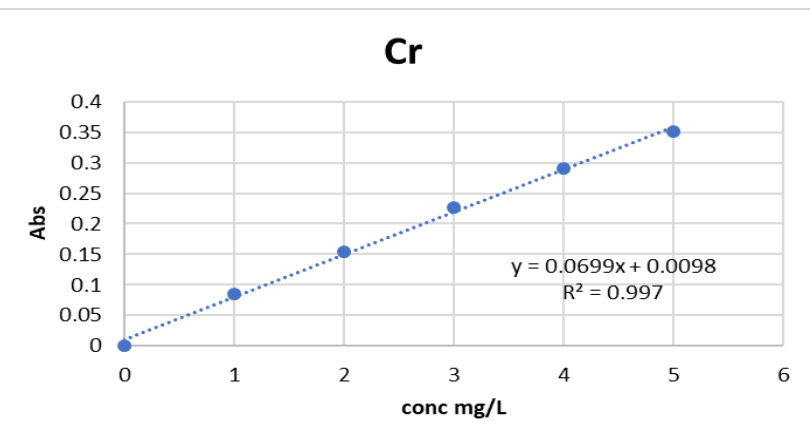

(a)

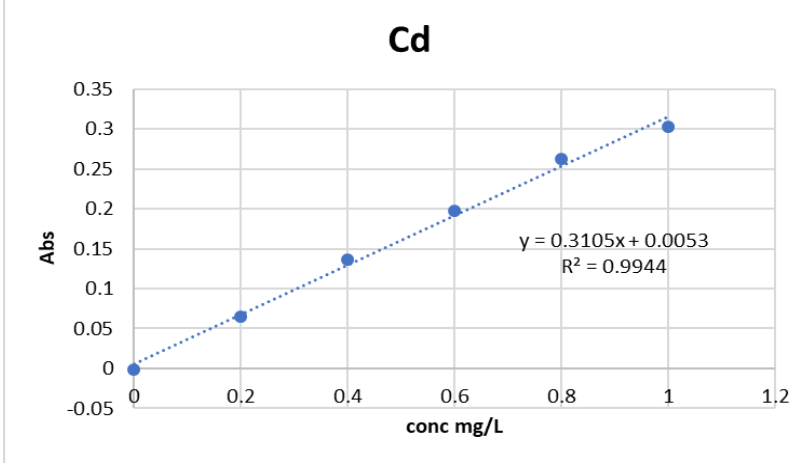

(b)

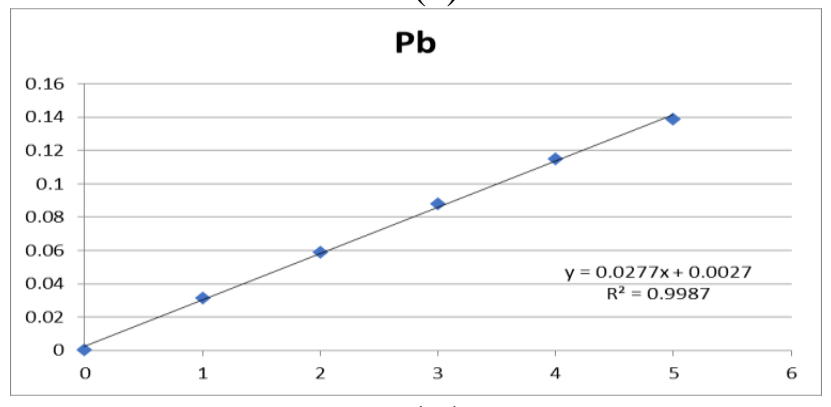

(c)

Gambar 1. Kurva baku untuk (a) Cr (b) $\mathrm{Cd}(\mathrm{c}) \mathrm{Pb}$

Tabel 2. Penurunan kadar limbah setelah penambahan variasi dosis eceng gondok (Eichornia crassipes).

\begin{tabular}{|c|c|c|c|c|c|}
\hline \multirow{2}{*}{ No } & \multirow{2}{*}{$\begin{array}{c}\text { Jenis } \\
\text { Logam }\end{array}$} & \multirow{2}{*}{$\begin{array}{c}\text { Kadar } \\
\text { awal }\end{array}$} & \multicolumn{3}{|c|}{ Kadar setelah penambahan serbuk eceng } \\
\cline { 4 - 6 } & & $0,25 \mathrm{~g}$ & $0,35 \mathrm{~g}$ & $0,45 \mathrm{~g}$ \\
\cline { 4 - 6 } & & Rata-rata & Rata-rata & Rata-rata \\
\hline 1 & $\mathrm{Cr}$ & 2,502 & $\mathbf{2 , 4 3 5 5}$ & $\mathbf{2 , 3 5 1 5}$ & $\mathbf{2 , 1 1 3 5}$ \\
\hline 2 & $\mathrm{Cd}$ & 1,090 & $\mathbf{0 , 9 4 9}$ & $\mathbf{0 , 9 4 1}$ & $\mathbf{0 , 9 3 5}$ \\
\hline 3 & $\mathrm{~Pb}$ & 0,753 & $\mathbf{0 , 6 7 4}$ & $\mathbf{0 , 6 7 0}$ & $\mathbf{0 , 6 6 9}$ \\
\hline
\end{tabular}


Hasil analisis menggunakan Spektrofotometer Serapan Atom berdasarkan pemberian serbuk daun eceng gondok (Eichornia crassipes) dapat dilihat, pada tabel 7.2 dosis serbuk 0,25 gram rata-rata penurunan kadar $\mathrm{Cr}$ yaitu 2,4355 ppm. Sedangkan pada pemberian serbuk 0,35 gram, rata-rata penurunan kadar $\mathrm{Cr}$ yaitu 2,3515 ppm.

Berdasarkan pemberian serbuk daun eceng gondok (Eichornia crassipes) dapat dilihat penurunan kadar $\mathrm{Cr}, \mathrm{Cd}$ dan $\mathrm{Pb}$ tertinggi yakni pada pemberian serbuk 0,45 gram dengan masing - masing rata - rata penurunan 2,1135, 0,935 dan 0,669. Sedangkan persen penurunan kadar $\mathrm{Cr}, \mathrm{Cd}$ dan $\mathrm{Pb}$ terendah yakni pada pemberian dosis serbuk daun eceng gondok 0,25 gram dengan penurunan 2,4355, 0,949 dan 0,674.

Penurunan kadar $\mathrm{Cr}, \mathrm{Cd}$ dan $\mathrm{Pb}$ setelah penambahan serbuk daun eceng gondok dapat dilihat pada Gambar 2 . Berdasarkan grafik tersebut, maka dapat dilihat bahwa semakin tinggi pemberian jumlah dosis serbuk pada limbah cair laboratorium dasar PPSDM MIGAS CEPU, semakin besar pula penurunan kadar $\mathrm{Cr}, \mathrm{Cd}$ dan $\mathrm{Pb}$.

Hal ini dapat disebabkan karena semakin tingginya tingkat dosis serbuk daun eceng gondok (Eichornia crassipes) yang di berikan pada perlakuan, maka semakin tinggi pula daya serap serbuk daun eceng gondok (Eichornia crassipes) terhadap penurunan kadar logam khususnya pada $\mathrm{Cr}, \mathrm{Cd}$ dan $\mathrm{Pb}$.
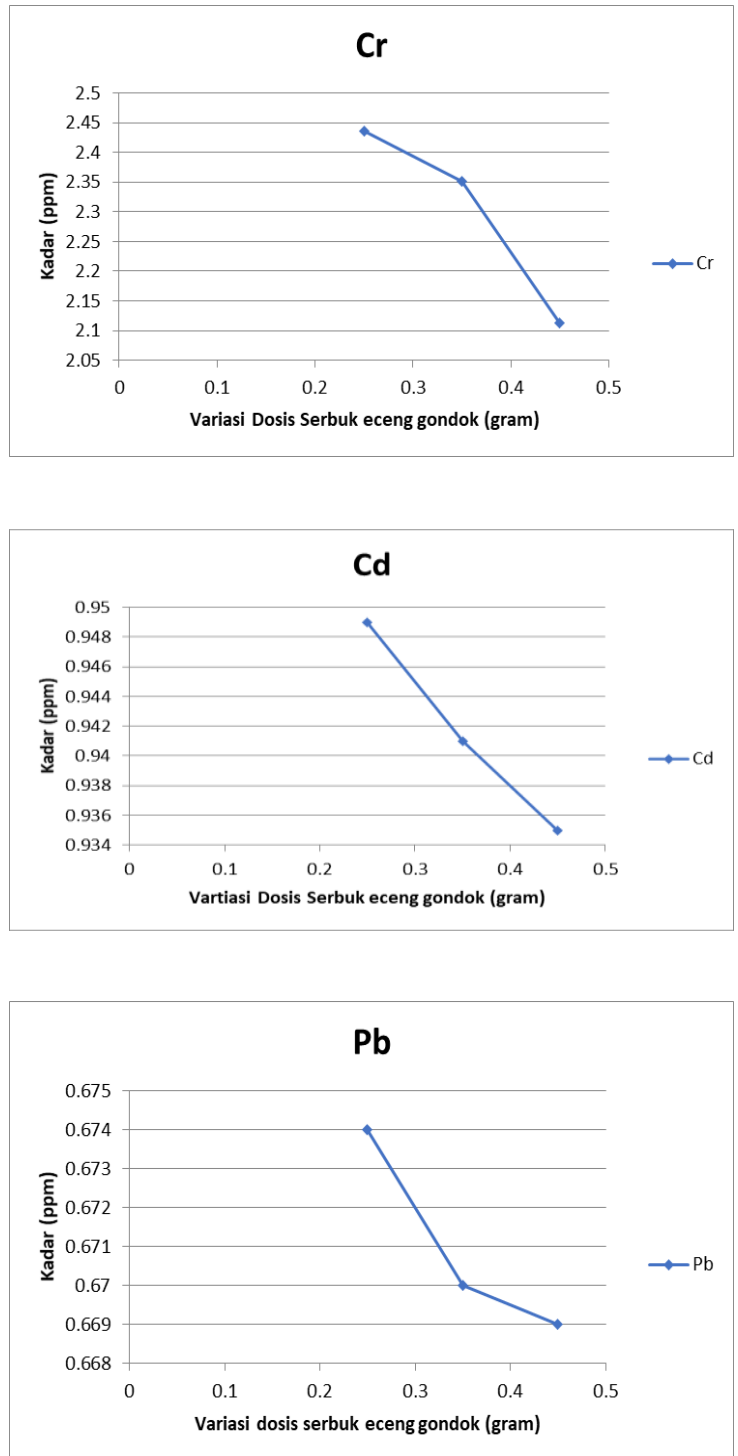

Gambar 2. Penurunan kadar $\mathrm{Cr}, \mathrm{Cd}$ dan $\mathrm{Pb}$ setelah pemberian serbuk eceng gondok (Eichornia crassipes).

Semakin banyak massa adsorben serbuk eceng gondok (Eichornia crassipes) maka lignin yang terkandung semakin banyak, sehingga kemampuan untuk 
menyerap logam semakin sedikit karena lignin dapat menghambat adsorpsi dan menghalangi proses transfer ion kesisi aktif adsorpsi. Selain itu serat eceng gondok sebagian besar tersusun dari selulosa.

Selulosa merupakan senyawa organik yang terdapat pada dinding sel bersama dengan lignin berperan untuk mengokohkan struktur tumbuhan. Struktur selulosa terdiri atas rantai panjang dari unit-unit glukosa yang terikat dengan ikatan 1,4- $\beta$-glukosida Ditinjau dari strukturnya, selulosa memiliki potensi yang cukup besar untuk dijadikan sebagai media menjerap karena kaya akan gugus $-\mathrm{OH}$ yang dapat berinteraksi dengan komponen adsorbat.

\section{Kesimpulan}

Berdasarkan hasil penelitian yang dilakukan selama melaksanakan praktek di PPSDM Migas Cepu untuk analisis penurunan kadar limbah cair laboratorium dasar PPSDM MIGAS CEPU dengan adsorpsi dari serbuk eceng gondok (Eichornia crassipes), dapat diambil kesimpulan berdasarkan berikut ini:

1. Limbah cair laboratorium dasar PPSDM MIGAS CEPU terdapat logam berat dengan konsentrasi $\mathrm{Pb}, \mathrm{Cd}$ dan $\mathrm{Cr}$ yakni sebesar 0,753, 1,090 dan 2,502 ppm.
2. Hasil analisis terhadap pengaruh pemberian dosis serbuk eceng gondok (Eichornia crassipes) pada limbah pemberian serbuk daun eceng gondok (Eichornia crassipes) dapat dilihat penurunan kadar yang efektif $\mathrm{Cr}, \mathrm{Cd}$ dan $\mathrm{Pb}$ yakni pada pemberian serbuk 0,45 gram dengan rata - rata penurunan 0,3885, 0,155 dan $0.084 \mathrm{ppm}$.

3. Hasil kadar limbah cair laboratorium dasar PPSDM MIGAS CEPU sebelum dan sesudah pemberian serbuk eceng gondok (Eichornia crassipes) pada logam Cr, dari 2,502 menjadi 2,1135. Cdm dari 1,090 menjadi 0,935 dan $\mathrm{Pb}$, dari 0,753 menjadi 0,669.

\section{Daftar Pustaka}

Darmono, 2010, Lingkungan Hidup dan Pencemaran, Hubungannya dengan Toksikologi Senyawa Logam. Universitas Indonesia (UIPress), Jakarta.

Syahrul M. 1998. Pengaruh Waktu dan pH Terhadap Pengikatan Logam Berat $\mathrm{Cd}, \mathrm{Hg}$, dan $\mathrm{Pb}$ Oleh Eceng gondok (Eichornia crassipes). Disertasi IPB-UH.

Fardiaz Srikandi. 2003. Polusi Air dan Udara. Kanisius. Bogor

Hasim. 2003. Eceng Gongok Pembersih Polutan Logam Berat. Kompas dalamkolom Inspirasi. Jakarta.

Nugraheni P, Trihadaningrum, Y., Pengaruh Sifat Payau Dan Kesadahan Sumber Air oleh Eceng gondok. Jurnal Kimia Lingkungan. Vol.3, No.2, 2002. 